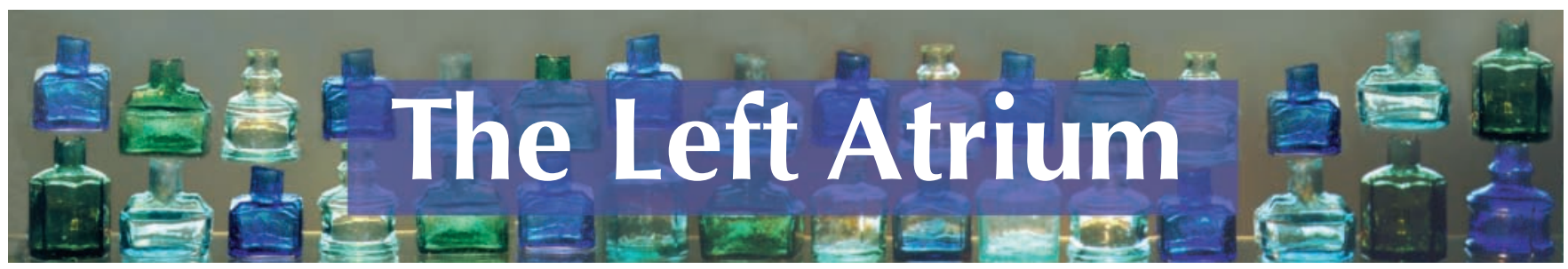

\section{The resident condition}

Staying human during residency training, third edition

Allan D. Peterkin

Toronto, Buffalo, London: University of Toronto Press; 2004

166 pp \$16 ISBN 0-8020-81487

$\mathrm{N}$ ot long ago I completed what for me was a pretty major home renovation project. This involved many visits to "how to" Internet sites, as well as several trips to a nearby big box whose advertising motto is "You can do it. We can help." Now I am embarking on my residency in family medicine, another daunting project, and one I approach with no small amount of trepidation. And so, for the last several days I have been reading the new (third) edition of Staying Human During Residency Training, a "how to" book by Toronto psychiatrist, family physician, and poet, $\mathrm{Al}-$ lan Peterkin.

A wise attending recently suggested to me that the cynicism that seems rampant among physician trainees and new physicians ought to be seen as a normal developmental stage, a necessary defence mechanism; once we are outfitted comfortably with our professional armamentarium, cynicism should give way to more mature coping strategies. This seems to me to be wonderful advice; nevertheless, I confess that I approached Peterkin's book with a very large degree of cynicism, for it struck me that he might be attempting to address a pervasive problem - the welldocumented dehumanizing effect of residency programs - by dealing with the "victims" rather than with a culpable system. (Besides, one could argue that the real victims might be our patients and families.)

In the same way that an advantage to growing up with older brothers is that one learns how to take a punch, $\mathrm{Pe}$ terkin suggests that the "potential risks 婷 [of residency] to both physical and

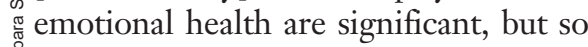
襄 are the opportunities to learn coping skills that will last throughout one's medical career." This is a hugely familiar refrain, and is very obviously true. But as we all presumably would be horrified to come upon a book such as, for example, Frisky Physicals: a Patients' Guide to Dealing with Lonely Physicians, I would argue that a book that purports to teach residents how to withstand what Peterkin refers to as "training toxicity" ought to be seen as a doubleedged sword.

That being said, and to Peterkin's credit, Staying Human includes "an appeal to educators," wherein it is noted that while the "book emphasizes residents' roles in ensuring their own wellbeing" this "focus alone is not complete." Fortunately for me, this appeal comes very early in the book, and seeing it attenuated my cynical skepticism enough to allow me to continue reading. It turns out that this little survival guide is chock full of tidbits useful for novice and seasoned veteran alike. Peterkin offers advice that ranges from the banal but significant "[k]eep your hands away from your eyes and face to reduce the incidence of viral infections," to the profoundly important "[i]f you make an error in an order, treatment, or procedure, do not attempt to hide it." He addresses financial matters as well as moral, ethical and legal issues. Nor does he shy away from such awkward subjects as residents' need for sexual intimacy, or things to be considered when seeking psy- chotherapy: "Remember to keep any receipts for income tax purposes, and to discuss with your therapist whether treatment will restrict medical/disability insurance access later on."

Inasmuch as this book appears to be intended as a reference for workers in a dangerous, albeit rewarding (mine)field, we should not be surprised to find that Peterkin has included numerous citations to books, journal articles and Web sites dedicated to the issues he addresses. These quite likely can be useful, and all the more so if they are used to prevent burn-out or other "situations" from developing. The irony, I think, is that those who will take the time to peruse this book may already be outside of its intended audience. That is, if you're willing to spend a day reading this (rather than Harrison's) before your internal medicine rotation, you may already have an understanding of Peterkin's central point.

That point, I think, is that while medical training can be gruelling, and while we do well to attempt to address its many systemic excesses (if and when we have time), there are numerous exigencies and contingencies, unexpected and unforeseeable, that are simply beyond our control. Where those who survive and thrive (those who grow through their cynicism) will have differed from their less fortunate colleagues will be in their ability to know and protect their boundaries. Those who, for instance, read a novel from Peterkin's selection of great "medical fiction" (the list includes Shaw's The Doctor's Dilemma, Solzhenitsyn's Cancer Ward and Shelley's Frankenstein), or go to the gym, or go to a movie with their partner, or read Peterkin's book — rather than busily 
finding and photocopying the latest journal article to present to their colleagues at rounds - will have learned that, to the extent that control is at all possible in our lives, it is at home, or at least away from the hospital, that it can and must be exerted.

We are necessarily a driven cohort, we physician-types. We jump hurdles to get through training and are daily swung from one trapeze to another. I think of Peterkin's book as a series of suggestions by means of which we can render residency training a little less like working without a net. Although his advice on how to navigate a number of common, difficult situations in the machine (or monster) that is the modern health care system is solid and almost certainly helpful, more important is the notion, implicit and explicit throughout his book, that if one works in a dangerous environment, one must necessarily be fit, careful and prepared.

Although I was initially disappointed by the relatively short shrift given by Peterkin's little survival guide to the many problems with how "the system" operates, I see now that this is yet another way in which he reminds us of the importance of understanding and accepting the distinction between those things we can change and those we cannot. Having said that, and at the risk of cliché, if we're not part of the solution, we're part of the problem.

\section{Ted St. Godard}

PGY1

Family Medical Centre

University of Manitoba

Winnipeg, Man.

\section{Room for a view}

\section{For whom the bell tolls}

$\mathrm{I}$ $\mathrm{t}$ is a long drive to this small town, so I we wait until there are enough new referrals to our geriatric psychiatry service to make the trip worthwhile. It has been six weeks since we were last here at the nursing home, and we have four new patients to see. Mary, the outreach nurse I work with, places her black briefcase on the desk at the nursing station before going down the hallway to find someone who can take the time to speak with us. I settle into the creaking chair behind the desk and consider whether to open the bag to look again at the charts we have brought with us. I reviewed them in the car as Mary drove us out here, but the view of the open water running endlessly beside the road distracted me, and all I can remember are fragments of the questions we are being asked. Someone cannot sleep. Someone else wants to go home. Thank you for seeing.

Mary comes back with Sandra, the nurse who works on the unit. We make small talk, taking our time before getting down to the list of patients. This man, poor old soul, fell out of bed and broke his hip. He was transferred to Halifax and won't be back for a while. This other man keeps hitting out at staff, they've tried everything, do we have any suggestions?

I like coming up here. At these rural nursing homes the staff know all the residents. They've known them their whole lives, in fact, and can tell you what they were like twenty years ago. This is why families want their loved ones admitted near home; not just so they are closer and easier to visit, but because the community stretches right into the nursing home and doesn't end at the door as it often seems to in the city. The residents are real peo-

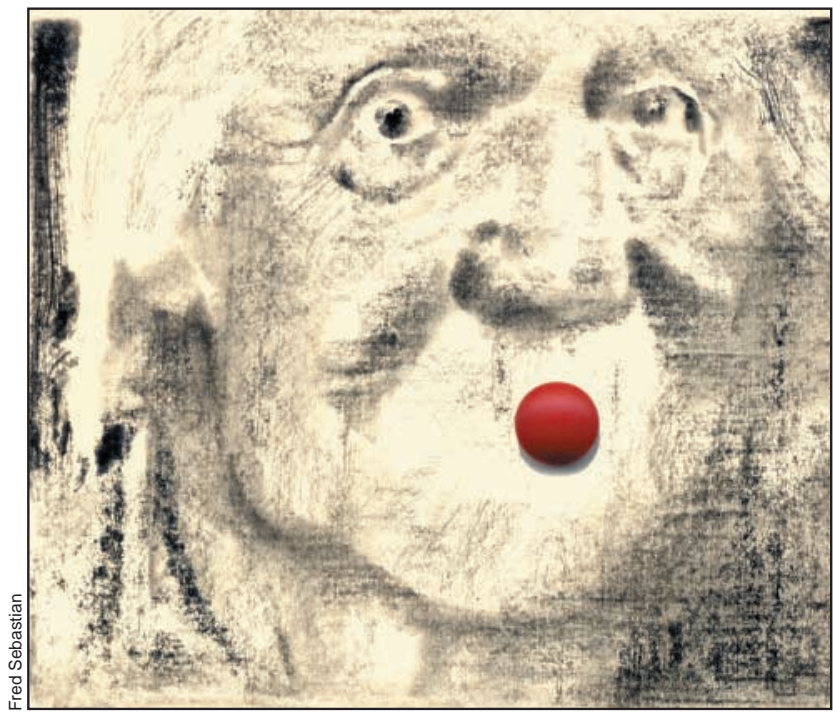
ple, not characters half-constructed from a history in a chart, or from stories told about them by others. There is no urban multitude of elderly demented patients in their wheelchairs and geri-chairs surrounding the nursing station like older-model vehicles in an enormous parking lot. There is no television endlessly looping the news of the day. In fact, the hallway is deserted except for one older gentleman leaning on the handrail attached to the wall, slowly wandering with the purposelessness of senility.

After we have finished going through the new referrals, I remember a question I had wanted to ask. "How is Mr.
Zwicker doing? Did that new medication make any difference?" I am curious but not hopeful. We had sent some samples up a few weeks earlier in an offlabel attempt to manage his intractable screaming. I hadn't really thought it would work, but you never know.

"He never got the medication," Sandra replies. "He died before it could be started."

"Really?" The medication we sent is expensive, difficult to get covered by the provincial drug plan. And I don't have any more samples left. "He never got it at all? Was the box even opened?"

"I doubt it." 